\title{
Assessment of Physical Activity in a Group of Adults in Italy: Comparison of Two Different Methodologies
}

\author{
Lorenzo Barnaba, Donatella Ciarapica, Angela Polito* \\ Council for Agricultural Research and Economics, Research Centre for Food and Nutrition, Rome, Italy \\ *Corresponding author: angela.polito@crea.gov.it
}

\begin{abstract}
Introduction: Physical activity levels are often monitored to assess health behaviours and their associations with health status, including mortality and morbidity rates in the population. The International Physical Activity Questionnaire (IPAQ-L) was developed in the late 1990s to obtain internationally comparable data on health related physical activity and several studies have shown its acceptable validity and reliability for population-based studies. The aim of this study was the comparison of the International Physical Activity Questionnaire (IPAQ-L) against an objective method such as accelerometry. Methods: 220 volunteers (105 men and 115 women), aged 18-65 years, were recruited. All volunteers wore an accelerometer for 7 consecutive days, after that, we required them to complete the IPAQ-L together with a lifestyle questionnaire containing questions on physical exercise, smoking habits, alcohol consumption and other demographic data (age, sex, ect). Moreover, we collected measure of weight $(\mathrm{kg})$ and height $(\mathrm{cm})$ according to the standard procedure; body mass index ( $\mathrm{kg}$ body weight $/ \mathrm{m}^{2}$ body height) has been calculated. Results: IPAQ-L showed a significant tendency to overestimate time spent in vigorous and moderate activities ( $\mathrm{p}=0.0000)$ and to underestimate time spent sitting $(\mathrm{p}=0.0000)$. Additionally, the differences in minutes per day of moderate and vigorous physical activities between the IPAQ-L and the accelerometer reported in questionnaire increased. Nevertheless, we found a low positive correlation $(r=0.30 ; \mathrm{p}<0.05)$ between total physical activity measured by accelerometer and that obtained by the IPAQ-L. Conclusions: Our results showed low to moderate correlations between IPAQ-L and accelerometer pointing out differences across physical activity categories. This is an aspect that should be taken into account prior to deciding on use of an instrument for the assessment of physical activity; especially in small population groups preference should come down to objective tools such as the accelerometer.
\end{abstract}

Keywords: physical activity, IPAQ-L, accelerometer, comparison

Cite This Article: Lorenzo Barnaba, Donatella Ciarapica, and Angela Polito, "Assessment of Physical Activity in a Group of Adults in Italy: Comparison of Two Different Methodologies." Journal of Physical Activity Research, vol. 2, no. 2 (2017): 117-123. doi: 10.12691/jpar-2-2-9.

\section{Introduction}

Physical activity (PA) levels are often monitored to assess health behaviours and their associations with health status, including mortality and morbidity rates in the population [1,2,3]. Regular and adequate levels of PA improve muscular and cardiorespiratory fitness, bone and functional health, reduce the risk of non-communicable diseases and depression and it's a key determinant of energy expenditure and thus fundamental to energy balance and weight control $[2,4,5,6]$.

Presently, numerous objective and subjective self-report instruments are available for assessing physical activity in population groups. Among the objective measurements, pedometers and accelerometers represent small device which can store data for multiple days and are increasingly reliable and affordable. In particular, accelerometers are small devices that provide objective measurements of PA via minute-by-minute recording of body acceleration. Although various accelerometer models are available that measure single- or multiple-axis movements, the basic technology is the same for all models: piezoelectric or piezoresistive materials produce electric signals when the devices are subject to acceleration. The devices have been shown to provide an optimum combination of ease of use and measurement accuracy. The ActiGraph accelerometer provides an objective and valid measure of time spent in sedentary, light moderate and vigorous intensities physical activity and is good reference method for assessing the validity of physical activity questionnaires. Subjective methods are useful in population studies as they are inexpensive and easy to apply but have their limitations such as reliability and validity problems associated with recall of activity [7]. Because of the limitations of questionnaires and the high cost and subject burden associated with direct observation and doubly labeled water, accelerometry has become the method of choice for objective, valid and reliable measurement in adults.

Several self-report questionnaires have been proposed [8] which rely on individuals' understanding and knowledge of the questions posed and their ability to accurately recall and record all physical activity; because of this, such questionnaires often prove to have varying rates of validity, which ultimately affects their usefulness in 
accurately assessing physical activity levels of populations. The International Physical Activity Questionnaire (IPAQ-L) was developed in the late 1990s to obtain internationally comparable data on health related physical activity [9] and several studies have shown its acceptable validity and reliability for population-based studies $[10,11]$. There are two forms of the IPAQ, a short (IPAQ-S) and a long (IPAQ-L), with both versions could be administered by interview or self-completed. The short form was designed for population surveillance of physical activity providing information on the time spent walking, in moderate and vigorous intensity physical activity and sitting; while the long form was designed to be appropriate for use in research that requires detailed information on different PA domains and time spent in sedentary activities [12]. In particular, the long form of IPAQ measures frequency, duration, and intensity of physical activity in four domains of life: work, transport, domestic and garden and leisuretime.

A review has summarized 23 validation studies targeting the short IPAQ with mixed results [13] and only few studies have assessed the validity of the long IPAQ, showing conflicting results [9,14]. IPAQ has been validated in several populations [14]. Only two studies have evaluated the reliability and validity of the Italian version of the questionnaire $[15,16]$. The studies are been conducted in small population group and one in clinical subjects.

The aim of this study was to compare physical activity scores arising from the IPAQ-L with an objective measure, an accelerometer, in order to verify the validity of the IPAQ-L in determining the physical activity levels in a sample of adult Italian general population.

\section{Materials and Method}

\subsection{Sampling}

220 volunteers (105 men and 115 women), aged 18-65 years, were recruited. After being informed about the purpose of the study, they gave their written consent. Volunteers wore an accelerometer for 7 consecutive days, after that, they to completed the long form of the International Physical Activity Questionnaire (IPAQ-L) together with a lifestyle questionnaire containing questions on physical exercise, smoking habits, alcohol consumption and demographic data. Moreover, volunteers underwent anthropometric measurements, according to the standard procedures. From the original sample, after cleaning the data for missing and out-of-range values according to the IPAQ-L Research Committee [17] and excluding also subjects with incomplete physical activity data or technical errors in the instrument, 205 subjects (96 men and 109 women) represent the final sample of the study. The study protocol was approved by the 'Sapienza' University of Rome Ethical Committee.

\subsection{Anthropometric Measurements}

Anthropometric measurements (height, body weight) were performed in the morning in fasting conditions by the same skilled observer according to the standardized procedure [18]. Height was measured to the nearest 0.1 $\mathrm{cm}$ with a metallic portable measuring board (Holtain Ltd, Crosswell, Crymych, United Kingdom). Body weight was recorded to the nearest $0.01 \mathrm{~kg}$ using a portable battery-operated weighing digital scale max $130 \mathrm{~kg}$ (SECA 813, Deutschland, Hamburg, Germany), regularly calibrated; each participant was barefoot and lightly dressed. Weight and height were used to calculate Body Mass Index (BMI, $\mathrm{kg} / \mathrm{m}^{2}$ ), and consequently the prevalence of obesity and overweight, using the cut-off points proposed for adult population: underweight $<18.5$ $\mathrm{kg} / \mathrm{m}^{2}$; overweight $25.0-29.9 \mathrm{~kg} / \mathrm{m}^{2}$ and obesity $\geq 30$ $\mathrm{kg} / \mathrm{m}^{2}[19]$.

\subsection{International Physical Activity Questionnaire}

For estimating the level of physical activity, the original English version of IPAQ-L was translated into Italian, then back translated into English, and administered by trained personnel in a face-to-face interview. The IPAQ-L, designed to assess the levels of habitual physical activity, consists of 27 questions referred to the previous 7 days covering 4 domains of physical activity (work-related physical activity, transport-related physical activity, domestic and gardening activities, and leisure-time physical activity). The items in IPAQ-L are structured to provide separate domain specific scores for walking, moderate-intensity and vigorous-intensity activity within each domain.

The results were presented as the estimation of energy expenditure in metabolic equivalent-minutes per day (MET-minutes/day), made by using the compendium of physical activities [20,21,22] which provides a classification of specific activities in MET. One MET represents the resting energy expenditure during quiet sitting and is commonly defined as $3.5 \mathrm{ml} \mathrm{O}_{2} \bullet \mathrm{kg}-1 \bullet \mathrm{min}-1$ or $\approx 250 \mathrm{~mL} / \mathrm{min}$ of oxygen consumed, which represents the average value for a standard person (70 kg). Obviously the oxygen consumption increases with activity intensity level, therefore the MET value increases with the intensity of physical activity (e.g. 1 MET = the rate of energy expenditure while at rest [sitting quietly], 2 MET = walking at $3 \mathrm{~km} / \mathrm{h}$ would require twice the energy that an average person consumes at rest). According to IPAQ-L scoring protocol [17], MET-minutes/day of specific activity (walking or moderate intensity activity or vigorous intensity activity) is computed by multiplying MET value of particular activity (3.3 for walking, 4.0 for moderate intensity activity, and 8.0 for vigorous intensity activity) with hours spent in that particular activity. Computation of the total scores for the long form requires the summation of the duration (in minutes) and frequency (days) for all the types of activities in all domains.

Only the activities lasting at least 10 minutes were taken into account. Domain specific scores or activity specific subscores may be calculated. Domain specific scores require the summation of the scores for walking, moderate-intensity and vigorous-intensity activities within the specific domain, whereas activity-specific scores require the summation of the scores for the specific type of activity across domains [17]. 


\subsection{Actigraph Accelerometer}

The Actigraph model GT1M (Actigraph, Pensacola FL, USA), a biaxial accelerometer that allows the detection of only those accelerations that lie between 0.05 to $2 \mathrm{~g}$ ( $\mathrm{g}=$ gravitational field), was used to provide objective measures of physical activity. Subjects were instructed to wear the accelerometer from when they woke up to going to bed during 7 consecutive days. Subjects were given instructions to wear the accelerometer attached to a belt and secured directly next to the skin at their lower back, close to the center of gravity. Data were considered complete if volunteers had accelerometer counts for at least 10 hours per day, for at least 4 days, including at least a weekend day [23,24]. On average the accelerometers were worn for $6.76 \pm 0.55$ days, and on those days they wore it for $851 \pm 119$ minutes per day, equalling approximately 14 hours per day. The accelerometer measures intensity and duration of physical activity as well as sedentary periods. The raw acceleration signal to counts per minute to get a generic measure of the intensity of physical activity.

The Actigraph data were analyzed using the specific software (Actilife, rel. 5.9.1). The data were then analyzed for minutes per day spent sedentary as well as in physical activity of low, moderate or high intensity, based on the application of count thresholds corresponding to these activities. Time spent on vigorous intensity ambulatory activities was estimated as the amount of time accumulated above 5724 counts/min [25]. Minutes per day spent on lifestyle moderate intensity activities was estimated as the amount of time accumulated between 760 and 5724 counts/minute [26]. Minutes spent sitting were estimated as the amount of time accumulated below 100 counts/minute during periods when the accelerometer have been worn [27]. Time spent on low intensity physical activity was consequently defined as minutes accumulated between 100 and 760 counts/minute.

The time spent on each activity level is presented as every minute that meets the specific criteria. Average intensity was calculated taking the total counts divided by the recorded time (counts/min) and this was considered as a weighted measure of total physical activity [28].

\subsection{Statistical Analysis}

Normality of distributions of variables was tested by Shapiro-Wilk test. Data are presents as mean values \pm standard deviation and interquartile ranges (IQR) in total and by sex, age, BMI and education. The Student T-Test was used to evaluate the differences in physical characteristics between sexes, while the comparison between the IPAQ-L and the ActiGraph scores was done using Spearman's rank correlation coefficients.

The Bland and Altman analysis [29] was used to provide an indication of the systematic and random error and the heteroscedasticity of the IPAQ-L measures of physical activity and 95\% limits of agreement were used for describing the total error between the two methods. Variables used for the Bland and Altman analysis were daily time spent in moderate, vigorous and sedentary activities according to IPAQ-L and the Actigraph. The differences between the instruments were tested with a paired nonparametric Wilcoxon test. The level of significance for all analysis was set at $\mathrm{P}<0.05$. Statistical analysis was performed by STATISTICA software (release 8; StatSoft Inc, Vigonza PD, Italy).

\section{Results}

A percentage (about 7\%) of questionnaires was filled in a partial or incorrect way, with a significant difference between sexes $\left(\chi^{2}=6.82, \mathrm{p}<0.01\right.$ ) (data not shown); thus the information collected cannot be used for the assessment of physical activity. From the original sample, 205 (96 men and 109 women) subjects represent the final sample of the study, whose physical characteristic are reported in Table 1 . There were statistically significant differences between men and women in weight and height and consequently in BMI values, which indicate an overweight status especially for men $\left(\mathrm{BMI}=26.9 \pm 3.5 \mathrm{~kg} / \mathrm{m}^{2}\right)$.

Table 1. Physical characteristic of the sample (mean value \pm standard deviation) $(\mathrm{n}=\mathbf{2 0 5})$

\begin{tabular}{|c|c|c|c|}
\hline & Men & Women & $\mathrm{P}$ \\
\hline $\mathrm{N}^{\circ}$ & 96 & 109 & \\
\hline Age (years) & $41.1 \pm 12.2$ & $40.4 \pm 12.2$ & n.s. \\
\hline Weight $(\mathrm{kg})$ & $80.5 \pm 13.7$ & $65.4 \pm 13.4$ & 0.0000 \\
\hline Height $(\mathrm{cm})$ & $172.9 \pm 8.6$ & $161.8 \pm 6.7$ & 0.0000 \\
\hline BMI $\left(\mathrm{kg} / \mathrm{m}^{2}\right)$ & $26.9 \pm 3.5$ & $25.1 \pm 5.4$ & 0.006 \\
\hline
\end{tabular}

Statistical analysis: Student T-test; n.s. = not significant

Table 2 shows descriptive data for the IPAQ-L and the ActiGraph instruments stratified by sex, age, BMI and education.

The IPAQ-L showed higher minutes per day in vigorous intensity activities $(\mathrm{P}=00000)$ and in moderate intensity activities + walk (n.s.) and lower minutes per day in sitting $(\mathrm{P}=0.0000)$ compared with the ActiGraph. These differences are confirmed even after considering sex, age, BMI and education. Men, older adults (aged more than 50 years), and those with primary school education spend more time in moderate and vigorous activity as reported from IPAQ-L and this is consistent with patterns on the accelerometer. Additionally, standard deviations around the means were substantially greater for the IPAQ-L, indicating a greater variance in self-reported activity levels.

Table 3 shows the Spearman rank order correlations for the time spent in physical activity from the IPAQ-L with time spent in similar activities from the Actigraph by sex. Modest, but significant correlations were observed for all the types of physical activities except for moderate intensity activity, which is significant only for men. However, all correlation coefficients are $<0.50$.

A deepening of the confrontation between the two methods was performed using analysis Bland \& Altman.

For a sedentary lifestyle (Figure 1 ) the difference is on average $-212 \pm 197$ minutes per day indicating that the IPAQ-L systematically underestimates the time spent in sedentary activities compared to the accelerometer. This underestimation does not vary in relation to the time dedicated to such activities. 
Table 2. Descriptive data (mean value \pm standard deviation and interquartile ranges) from IPAQ-L and Actigraph, by sex, age, BMI and education

\begin{tabular}{|c|c|c|c|c|c|c|c|c|}
\hline & \multicolumn{2}{|c|}{ Vigorous intensity activity } & \multicolumn{2}{|c|}{ Moderate intensity activity + Walk } & \multicolumn{2}{|c|}{ Sitting } & \multicolumn{2}{|c|}{ Total physical activity } \\
\hline & $\begin{array}{c}\text { IPAQ-L } \\
\text { (min/day) }\end{array}$ & $\begin{array}{l}\text { Actigraph } \\
\text { (min/day) }\end{array}$ & $\begin{array}{l}\text { IPAQ-L } \\
\text { (min/day) }\end{array}$ & $\begin{array}{l}\text { Actigraph } \\
\text { (min/day) }\end{array}$ & $\begin{array}{l}\text { IPAQ-L } \\
\text { (min/day) }\end{array}$ & $\begin{array}{l}\text { Actigraph } \\
\text { (min/day) }\end{array}$ & $\begin{array}{c}\text { IPAQ-L } \\
\text { (MET-min/day) }\end{array}$ & $\begin{array}{c}\text { Actigraph } \\
\text { (counts/min) }\end{array}$ \\
\hline All & $\begin{array}{l}26 \pm 47^{d} \\
(0 ; 32)\end{array}$ & $\begin{array}{l}1 \pm 5^{d} \\
(0 ; 0)\end{array}$ & $\begin{array}{l}133 \pm 92 \\
(60 ; 195)\end{array}$ & $\begin{array}{l}124 \pm 61 \\
(83 ; 151)\end{array}$ & $\begin{array}{l}268 \pm 177^{d} \\
(154 ; 334)\end{array}$ & $\begin{array}{l}494 \pm 117^{d} \\
(420 ; 574)\end{array}$ & $\begin{array}{l}664 \pm 821^{\mathrm{d}} \\
(109 ; 901)\end{array}$ & $\begin{array}{l}266 \pm 154^{\mathrm{d}} \\
(138 ; 371)\end{array}$ \\
\hline \multicolumn{9}{|c|}{ Sex } \\
\hline Men & $\begin{array}{l}40 \pm 57^{d} \\
(0 ; 51)\end{array}$ & $\begin{array}{l}2 \pm 7^{d} \\
(0 ; 0)\end{array}$ & $\begin{array}{l}126 \pm 94 \\
(58 ; 188)\end{array}$ & $\begin{array}{l}131 \pm 67 \\
(83 ; 154)\end{array}$ & $\begin{array}{l}270 \pm 169^{d} \\
(154 ; 334)\end{array}$ & $\begin{array}{l}491 \pm 122^{d} \\
(393 ; 599) \\
\end{array}$ & $\begin{array}{l}714 \pm 891^{\mathrm{d}} \\
(84 ; 969)\end{array}$ & $\begin{array}{l}269 \pm 165^{\mathrm{d}} \\
(124 ; 380)\end{array}$ \\
\hline Women & $\begin{array}{l}14 \pm 32^{d} \\
(0 ; 13)\end{array}$ & $\begin{array}{l}1 \pm 4^{d} \\
(0 ; 0)\end{array}$ & $\begin{array}{l}140 \pm 90^{a} \\
(62 ; 197)\end{array}$ & $\begin{array}{l}119 \pm 55^{a} \\
(83,149)\end{array}$ & $\begin{array}{l}266 \pm 185^{d} \\
(154 ; 343)\end{array}$ & $\begin{array}{l}497 \pm 113^{d} \\
(452 ; 564)\end{array}$ & $\begin{array}{l}620 \pm 756^{\mathrm{d}} \\
(123,841)\end{array}$ & $\begin{array}{l}263 \pm 146^{\mathrm{d}} \\
(145 ; 364)\end{array}$ \\
\hline \multicolumn{9}{|c|}{ Age (years) } \\
\hline$<35$ & $\begin{array}{l}29 \pm 49^{d} \\
(0 ; 34)\end{array}$ & $\begin{array}{l}1 \pm 3^{d} \\
(0 ; 1)\end{array}$ & $\begin{array}{l}106 \pm 93 \\
(36 ; 146)\end{array}$ & $\begin{array}{l}113 \pm 53 \\
(80 ; 141)\end{array}$ & $\begin{array}{l}301 \pm 177^{d} \\
(154 ; 407)\end{array}$ & $\begin{array}{l}498 \pm 119^{d} \\
(450 ; 591)\end{array}$ & $\begin{array}{l}489 \pm 698^{\mathrm{b}} \\
(98 ; 515)\end{array}$ & $\begin{array}{l}211 \pm 137^{\mathrm{b}} \\
(94 ; 326)\end{array}$ \\
\hline $35-50$ & $\begin{array}{l}19 \pm 38^{d} \\
(0 ; 26)\end{array}$ & $\begin{array}{l}2 \pm 6^{d} \\
(0 ; 0)\end{array}$ & $\begin{array}{c}132 \pm 80 \\
(62 ; 188)\end{array}$ & $\begin{array}{c}130 \pm 69 \\
(78 ; 155)\end{array}$ & $\begin{array}{l}267 \pm 213^{d} \\
(154 ; 300)\end{array}$ & $\begin{array}{l}484 \pm 109^{d} \\
(415 ; 558)\end{array}$ & $\begin{array}{l}690 \pm 806^{\mathrm{d}} \\
(139 ; 901)\end{array}$ & $\begin{array}{l}273 \pm 165^{\mathrm{d}} \\
(138 ; 371)\end{array}$ \\
\hline$>50$ & $\begin{array}{l}31 \pm 54^{d} \\
(0 ; 39)\end{array}$ & $\begin{array}{l}1 \pm 7^{d} \\
(0 ; 0)\end{array}$ & $\begin{array}{l}170 \pm 92^{c} \\
(101 ; 231) \\
\end{array}$ & $\begin{array}{l}132 \pm 58^{c} \\
(87 ; 173) \\
\end{array}$ & $\begin{array}{l}226 \pm 112^{d} \\
(120 ; 266) \\
\end{array}$ & $\begin{array}{l}500 \pm 123^{d} \\
(414 ; 581)\end{array}$ & $\begin{array}{l}857 \pm 944^{\mathrm{d}} \\
(196 ; 1122) \\
\end{array}$ & $\begin{array}{l}326 \pm 141^{\mathrm{d}} \\
(220 ; 395)\end{array}$ \\
\hline \multicolumn{9}{|c|}{$\operatorname{BMI}\left(\mathrm{kg} / \mathrm{m}^{2}\right)$} \\
\hline$<25$ & $\begin{array}{l}23 \pm 41^{b} \\
(0 ; 26)\end{array}$ & $\begin{array}{l}1 \pm 3^{b} \\
(0 ; 1)\end{array}$ & $\begin{array}{l}129 \pm 92 \\
(58 ; 189)\end{array}$ & $\begin{array}{c}124 \pm 66 \\
(83 ; 150)\end{array}$ & $\begin{array}{l}281 \pm 214^{d} \\
(141 ; 339)\end{array}$ & $\begin{array}{l}495 \pm 122^{d} \\
(430 ; 571)\end{array}$ & $\begin{array}{l}572 \pm 671^{\mathrm{d}} \\
(114 ; 866)\end{array}$ & $\begin{array}{l}244 \pm 155^{\mathrm{d}} \\
(118 ; 345)\end{array}$ \\
\hline 25-29,9 & $\begin{array}{l}26 \pm 47^{b} \\
(0 ; 34)\end{array}$ & $\begin{array}{l}3 \pm 9^{b} \\
(0 ; 0)\end{array}$ & $\begin{array}{l}132 \pm 95 \\
(60 ; 197)\end{array}$ & $\begin{array}{l}126 \pm 55 \\
(79 ; 153)\end{array}$ & $\begin{array}{l}259 \pm 127^{d} \\
(180 ; 343)\end{array}$ & $\begin{array}{l}491 \pm 109^{d} \\
(420 ; 569)\end{array}$ & $\begin{array}{l}646 \pm 790^{c} \\
(86 ; 881)\end{array}$ & $\begin{array}{l}282 \pm 153^{c} \\
(149 ; 379)\end{array}$ \\
\hline$>30$ & $\begin{array}{l}35 \pm 63^{b} \\
(0 ; 30)\end{array}$ & $\begin{array}{l}0 \pm 1^{b} \\
(0 ; 0)\end{array}$ & $\begin{array}{l}149 \pm 87 \\
(84 ; 213) \\
\end{array}$ & $\begin{array}{c}122 \pm 55 \\
(83 ; 152) \\
\end{array}$ & $\begin{array}{l}245 \pm 134^{d} \\
(156 ; 313)\end{array}$ & $\begin{array}{l}495 \pm 121^{d} \\
(408 ; 580)\end{array}$ & $\begin{array}{l}960 \pm 1162^{\mathrm{c}} \\
(161 ; 1463) \\
\end{array}$ & $\begin{array}{l}298 \pm 151^{\mathrm{c}} \\
(179 ; 384)\end{array}$ \\
\hline \multicolumn{9}{|c|}{ Education } \\
\hline Primary & $\begin{array}{l}35 \pm 58^{c} \\
(0 ; 51)\end{array}$ & $\begin{array}{l}1 \pm 7^{c} \\
(0 ; 0)\end{array}$ & $\begin{array}{c}181 \pm 70^{a} \\
(124 ; 225)\end{array}$ & $\begin{array}{c}155 \pm 68^{a} \\
(102 ; 186)\end{array}$ & $\begin{array}{l}223 \pm 130^{d} \\
(137 ; 240)\end{array}$ & $\begin{array}{l}452 \pm 115^{d} \\
(375 ; 548)\end{array}$ & $\begin{array}{c}1086 \pm 1071^{d} \\
(325 ; 1693)\end{array}$ & $\begin{array}{l}332 \pm 152^{d} \\
(218 ; 395)\end{array}$ \\
\hline Secondary & $\begin{array}{l}26 \pm 47^{c} \\
(0 ; 34)\end{array}$ & $\begin{array}{l}1 \pm 4^{c} \\
(0 ; 0)\end{array}$ & $\begin{array}{l}142 \pm 100 \\
(62 ; 204)\end{array}$ & $\begin{array}{c}129 \pm 63 \\
(82 ; 153)\end{array}$ & $\begin{array}{l}235 \pm 139^{d} \\
(120 ; 300)\end{array}$ & $\begin{array}{l}491 \pm 114^{d} \\
(420 ; 558)\end{array}$ & $\begin{array}{c}711 \pm 798^{d} \\
(121 ; 1053)\end{array}$ & $\begin{array}{l}277 \pm 153^{d} \\
(142 ; 377)\end{array}$ \\
\hline University & $\begin{array}{c}22 \pm 40^{c} \\
(0 ; 23)\end{array}$ & $\begin{array}{l}2 \pm 6^{c} \\
(0 ; 1)\end{array}$ & $\begin{array}{c}93 \pm 75 \\
(36 ; 127)\end{array}$ & $\begin{array}{c}100 \pm 43 \\
(73 ; 121)\end{array}$ & $\begin{array}{l}342 \pm 222^{d} \\
(219 ; 407)\end{array}$ & $\begin{array}{l}527 \pm 109^{d} \\
(477 ; 611)\end{array}$ & $\begin{array}{l}348 \pm 509^{\mathrm{a}} \\
(83 ; 377)\end{array}$ & $\begin{array}{l}212 \pm 140^{\mathrm{a}} \\
(110 ; 260)\end{array}$ \\
\hline
\end{tabular}

Statistical analysis: Student T-test; a $\mathrm{p}<0.05$; b $\mathrm{p}<0.01$; c $\mathrm{p}<0.0005$; d $\mathrm{p}<0.0001$.

Table 3. Spearman Rank Correlation (Rs) for total physical activity and time spent in physical Activity from IPAQ-L and Actigraph.

\begin{tabular}{|l|c|c|c|}
\hline IPAQ-L -L (min/day) vs. Actigraph (min/day) & Total & Men & Women \\
\hline Vigorous intensity activity & $0.24^{*}$ & $0.20^{*}$ & $0.23^{*}$ \\
\hline Moderate intensity activity & 0.09 & $0.22^{*}$ & 0.02 \\
\hline Moderate intensity activity+walk & $0.37^{*}$ & $0.31^{*}$ & $0.44^{*}$ \\
\hline Sitting & $0.39^{*}$ & $0.47^{*}$ & $0.33^{*}$ \\
\hline Total physical activity* & $0.30^{*}$ & $0.21^{*}$ & $0.39^{*}$ \\
\hline
\end{tabular}

Statistical analysis: Student T-test; n.s. = not significant

*IPAQ-L total PA (MET-min/day), Actigraph total PA (counts/min)

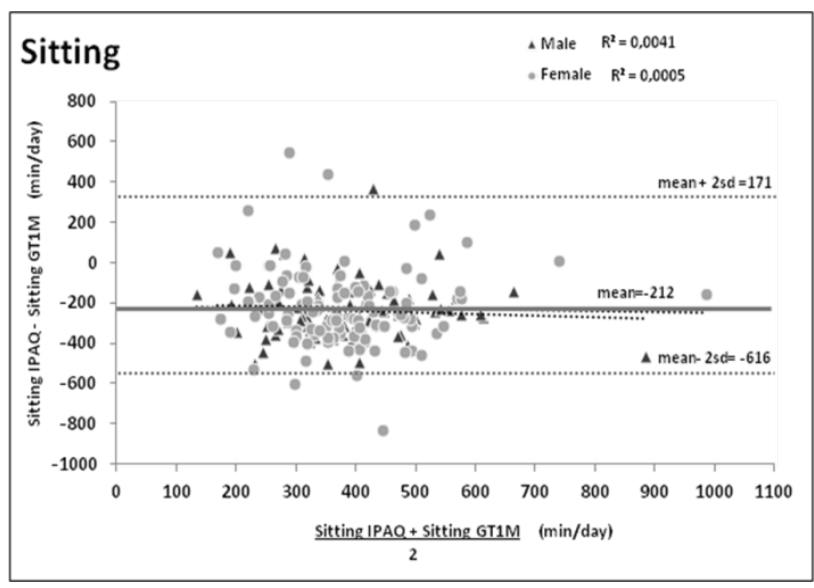

Figure 1. Bland-Altman analysis for differences between times spent in sedentary activities by IPAQ-L estimated or measured with accelerometer (min/day).
For moderate type activity (Figure 2) the difference is on average $57 \pm 68$ minutes per day indicating that the systematic overestimation IPAQ-L long as you perform moderate type activities compared to the accelerometer. This overestimation varies significantly $(p<0.0001)$ in relation to the time devoted to that activity.

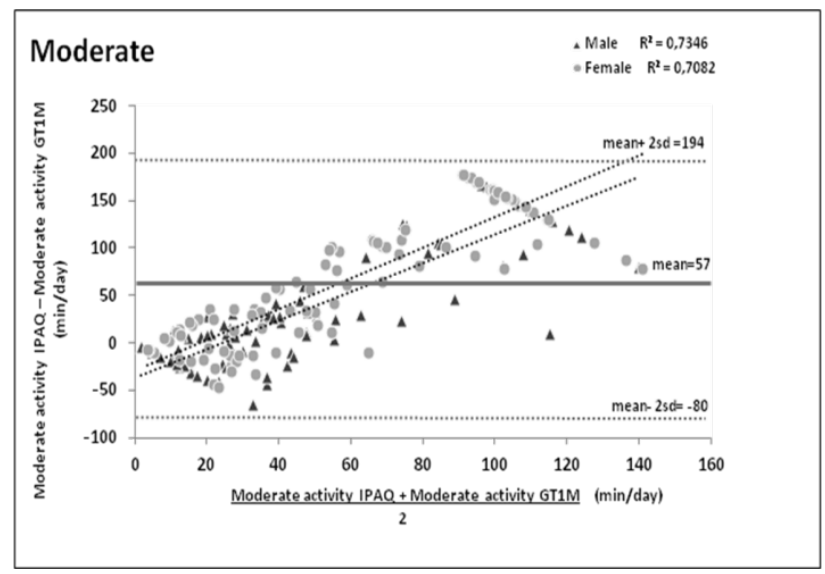

Figure 2. Bland-Altman analysis for differences between times spent in moderate-intensity activities estimated by the IPAQ-L or measured with accelerometer (min/day).

For vigorous activity type (Figure 3 ) the difference is on average $22 \pm 45$ minutes per day, indicating that even for this activity the IPAQ-L systematically overestimates the time compared to the accelerometer. This overestimation 
varies significantly ( $p<0.0001)$ in relation to the time devoted to that activity.

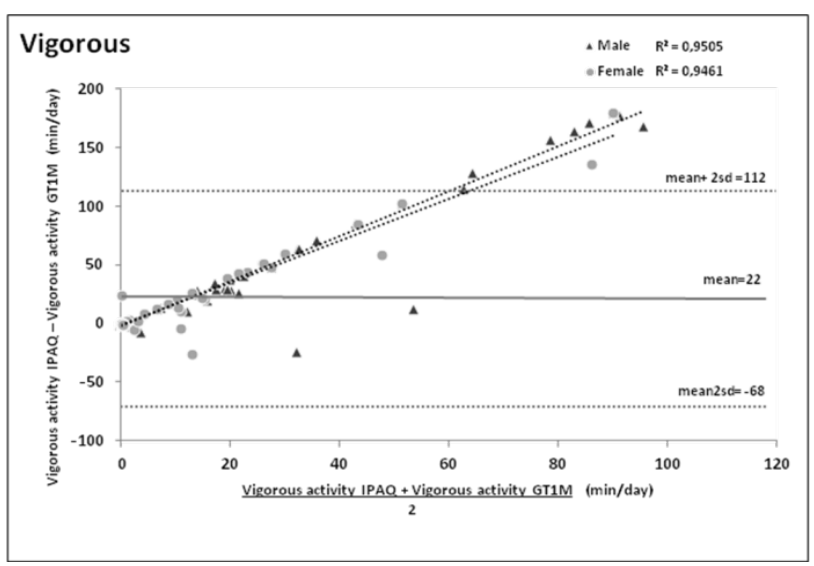

Figure 3. Bland-Altman analysis for differences between times spent in vigorous-intensity activity estimated by the IPAQ-L or measured with accelerometer (min/day)

\section{Discussion}

In this study, we were compared to the levels of physical activity obtained through the use of the questionnaire International physical activity (IPAQ-L) with an objective method which the accelerometer, in a sample of adult subjects of both sexes, in order to establish the validity of the IPAQ-L to the accelerometer. The accelerometers appear to be among the best measurement tools for the comparison of subjective methods as the questionnaire IPAQ-L $[30,31]$ although for many that is criticized the accelerometer and the IPAQ-L using different units [32]. The results show a significant correlation, even if low, between the total physical activity measured with the accelerometer and the one obtained from the IPAQ-L questionnaire. Correlation coefficients ranged from 0.22 to 0.47 between the IPAQ-L and the accelerometer and these outcomes are similar to those reported by Craig et al. [10] and Hagströmer et al. [28]. In several studies a value of 0.5 was assumed as the minimum recommended acceptable correlation between objective activity-measuring devices and questionnaires $[33,34,35]$. However, no study reached this minimum value [13] and Lee et al. [36] concluded that a 0.3-0.4 correlation could be a reasonable criterion for the validity of a body question on physical activity against a mechanical device that detects body movement. It emerged also significant trend IPAQ-L to overestimate the time spent on physical activities type vigorous and moderate ( $p=0.0000$ ), as was also observed by Boon et al. [37], and to underestimate the time spent sitting ( $p=0.0000)$ [38]. The higher correlations found in the present study for vigorous intensity compared to moderate intensity physical activity seem to confirm these assertions from previous studies [14]. The differences between the two types of measurement are due to that the accelerometer measures the movement of the body, while the IPAQ-L prompts me to make a recall of perceived exertion, in terms of intensity and duration, for certain types of activities. It is appropriate to highlight how difficult it is to get a good estimate of the low and moderate physical activity intensity as these have a wide variety and as one another at different times of day and week so that it is difficult to remember when filling out the survey. Instead, the physical activity of high intensity, so as to sit part of precise moments in a day and are therefore easier to remember. Finally, capabilities individual of the person who compiles them and his level of understanding, as well as age, are more conditioning factors faced by the selfadministered questionnaires. On the other hand, some of the activities listed in the IPAQ-L questionnaire such as heavy manual work, some housework, bike and body building not resulting in an acceleration of the body are not detected accelerometer, a fact that may lead to an underestimation of the activity actually performed. The differences in the minutes of moderate to vigorous physical activity daily reported between the IPAQ-L and the accelerometer increases with increasing time spent in the various activities. This figure is also confirmed by the study of Hagströmer et al. [28] and shows a tendency to overestimate physical activity carried out. These results may be a reflection of the difficulty remembering the time spent on each activity within a week as well as the effect of a distorted perception of the actual intensity of a physical activity in the presence of a high body weight and/or a low aerobic capacity $[23,26]$.

Analyzing the data to sedentary activities no differences vs. time are observed, unlike the Swedish population sample analyzed by Hagströmer et al. [28] in which there is also an overestimation of sedentary activity and an increase of the differences in relation to time. In addition, IPAQ-L is not able to correctly classify inactive participants in the present study; it yielded similar patterns of sedentary time as captured by accelerometer across only for education; different from the results of Oyeyemi et al. [38].

Despite the wide limits of agreement observed in the Bland- Altman plots, the scores reported for total physical activity from the IPAQ-L tend to follow similar demographic patterns as recorded on the accelerometer. Total physical activity reported on both instruments increased with increasing age and BMI, while decrease with the level of education and was lower among women than men.

\section{Conclusion}

In conclusion, our results showed a low to moderate correlation between the IPAQ-L and accelerometer, but it was still marked differences between the different categories of physical activities, an aspect that should be taken into account before deciding to use or not a tool such as the IPAQ-L. However being the IPAQ-L a selfadministered questionnaire, the perception of time dedicated to the various types of activities is conditioned by a subjectivity that can be particularly strong in some population groups (elderly, obese individuals with low educational level). There administration by an experienced operator can reduce this error [39]. Alternatively, and especially in studies of small groups of the population, preference should fall on objective tools such example, the accelerometer. 


\section{Acknowledgements}

This study was supported by the Italian Ministry of Agricultural, Food and Forestry Policies in the framework of the PALINGENIO and DEDIPAC projects.

\section{References}

[1] Blair, S. N, "Physical inactivity: the biggest public health problem of the 21st century”. British journal of sports medicine, 43(1), 1-2. 2009.

[2] Warburton, D. E., Nicol, C. W., \& Bredin, S. S, "Health benefits of physical activity: the evidence". Canadian medical association journal, 174 (6), 801-809. 2006.

[3] World Health Organization. "Physical activity. Fact sheet N 385."Retrieved from. 2014.

[4] World Health Organization, Global recommendations on physical activity for health. Geneva, Switzerland. 2010.

[5] Gregg, E. W., Gerzoff, R. B., Caspersen, C. J., Williamson, D. F., \& Narayan, K. V, "Relationship of walking to mortality among US adults with diabetes". Archives of internal medicine, 163(12), 1440-1447. 2003.

[6] Powell, K. E., Paluch, A. E., \& Blair, S. N, "Physical activity for health: What kind? How much? How intense? On top of what?" Annual review of public health, 32: 349-365. 2011.

[7] Warren, J. M., Ekelund, U., Besson, H., Mezzani, A., Geladas, N., \& Vanhees, L, "Assessment of physical activity-a review of methodologies with reference to epidemiological research: a report of the exercise physiology section of the European Association of Cardiovascular Prevention and Rehabilitation”. European Journal of Cardiovascular Prevention \& Rehabilitation, 17(2), 127-139. 2010.

[8] Pereira, M. A., FitzGerald, S. J., Gregg, E. W., Joswiak, M. L., Ryan, W. J., Suminski, R. R., Zmuda, J. M, "A collection of physical activity questionnaires for health-related research". Med. Sci. Sports Exerc, 29(6 Suppl.): S1-205. 1997.

[9] Loyen, A., Van Hecke, L., Verloigne, M., Hendriksen, I., Lakerveld, J., Steene-Johannessen, J., Deforche, B, "Variation in population levels of physical activity in European adults according to cross-European studies: a systematic literature review within DEDIPAC”. International Journal of Behavioral Nutrition and Physical Activity, 13(1), 72. 2016.

[10] Craig, C. L., Marshall, A. L., Sjöström, M., Bauman, A. E., Booth, M. L., Ainsworth, B. E., Oja, P, "International physical activity questionnaire: 12 -country reliability and validity". Medicine \& Science in Sports \& Exercise, 35(8), 1381-1395. 2003.

[11] Deng, H. B., Macfarlane, D. J., Thomas, G. N., Lao, X. Q., Jiang, C. Q., Cheng, K. K., Lam, T. H, "Reliability and validity of the IPAQ-Chinese: the Guangzhou Biobank Cohort study". Medicine \& Science in Sports \& Exercise, 40(2), 303-307.2008.

[12] Oyeyemi, A. L., Bello, U. M., Philemon, S. T., Aliyu, H. N., Majidadi, R. W., \& Oyeyemi, A. Y, "Examining the reliability and validity of a modified version of the International Physical Activity Questionnaire, long form (IPAQ-LF) in Nigeria: a crosssectional study". BMJ open, 4(12), e005820.2014.

[13] Lee, P.H., Macfarlane, D.J., Lam, T., Stewart, S.M, "Validity of the international physical activity questionnaire short form (IPAQSF): a systematic review”. Int. J. Behav. Nutr. Phys. Act. 8, 115. 2011.

[14] Wanner, M., Probst-Hensch, N., Kriemler, S., Meier, F., Autenrieth, C., Martin, B.W, "Validation of the long international physical activity questionnaire: influence of age and language region”. Preventive medicine reports, 3, 250-256.2016.

[15] Mannocci, A., Di Thiene, D., Del Cimmuto, A., Masala, D., Boccia, A., De Vito, E., la Torre, G, "International Physical Activity Questionnaire: validation and assessment in an Italian sample”. Italian Journal of Public Health, 7, 4, 369-376. 2010.

[16] Minetto, M. A., Motta, G., Gorji, N. E., Lucini, D., Biolo, G., Pigozzi, F., Maffiuletti, N. A, "Reproducibility and validity of the Italian version of the International Physical Activity Questionnaire in obese and diabetic patients". Journal of Endocrinological Investigation, 1-7. 2017.
[17] International Physical Activity Questionnaire (IPAQ-L). IPAQ-L Research Committee, 2005., available at https://sites.google.com/site/theipaq/

[18] Lohman, T. G., Roche, A. F., \& Martorell, R, Anthropometric standardization reference manual. Human kinetics books. 1988.

[19] World Health Organization, Physical status: The use of and interpretation of anthropometry, Report of a WHO Expert Committee. 1995.

[20] Ainsworth, B. E., Haskell, W. L., Leon, A. S., Jacobs Jr, D. R., Montoye, H. J., Sallis, J. F., \& Paffenbarger Jr, R. S, "Compendium of physical activities: classification of energy costs of human physical activities". Medicine and science in sports and exercise, 25(1), 71-80. 1993.

[21] Ainsworth, B. E., Haskell, W. L., Whitt, M. C., Irwin, M. L., Swartz, A. M., Strath, S. J., Jacobs, D. R,. "Compendium of physical activities: an update of activity codes and MET intensities". Medicine and science in sports and exercise, 32 (9;SUPP/1), S498-S504. 2000.

[22] Ainsworth, B. E., Haskell, W. L., Herrmann, S. D., Meckes, N., Bassett Jr, D. R., Tudor-Locke, C., Leon, A. S,. "Compendium of Physical Activities: a second update of codes and MET values". Medicine and science in sports and exercise, 43(8), 1575-1581. 2011.

[23] Trost, S. G., Pate, R. R., Freedson, P. S., Sallis, J. F., Taylor, W. C, "Using objective physical activity measures with youth: how many days of monitoring are needed?”. Medicine \& Science in Sports \& Exercise, 32(2), 426. 2000.

[24] Trost, S. G., McIver, K. L., Pate, R. R, "Conducting accelerometer-based activity assessments in field-based research". Medicine \& Science in Sports \& Exercise, 37(11), S531-S543. 2005.

[25] Freedson, P. S., Melanson, E., \& Sirard, J, "Calibration of the Computer Science and Applications, Inc. accelerometer". Medicine and science in sports and exercise, 30(5), 777-781. 1998

[26] Matthew, C. E, "Calibration of accelerometer output for adults". Medicine and science in sports and exercise, 37(11 Suppl), S51222. 2005.

[27] Matthews, C. E., Chen, K. Y., Freedson, P. S., Buchowski, M. S., Beech, B. M., Pate, R. R., \& Troiano, R. P, “Amount of time spent in sedentary behaviors in the United States, 2003-2004".American journal of epidemiology, 167(7), 875-881. 2008.

[28] Hagstromer, M., Ainsworth, B. E., Oja, P., Sjostrom, M., "Comparison of a subjective and an objective measure of physical activity in a population sample". Journal of Physical Activity and Health, 7 (4), 541-550. 2010.

[29] Bland, J. M., \& Altman, D, "Statistical methods for assessing agreement between two methods of clinical measurement". The Lancet, 327 (8476), 307-310. 1986.

[30] Sirard, J. R., \& Pate, R. R, "Physical activity assessment in children and adolescents”. Sports medicine, 31 (6), 439-454. 2001.

[31] Welk, G, Physical assessment in health-related research. UK: Human Kinetics. Leeds, 2002.

[32] Ham, S. A., Reis, J. P., Strath, S. J., Dubose, K. D., \& Ainsworth, B. E, "Discrepancies between methods of identifying objectively determined physical activity". Medicine and science in sports and exercise, 39(1), 52-58. 2007.

[33] Chinapaw, M. J., Mokkink, L. B., van Poppel, M. N., van Mechelen, W., \& Terwee, C. B, "Physical activity questionnaires for youth”. Sports Medicine, 40 (7), 539-563. 2010.

[34] Forsén, L., Loland, N. W., Vuillemin, A., Chinapaw, M. J., van Poppel, M. N., Mokkink, L. B.,Terwee, C. B, "Self-administered physical activity questionnaires for the elderly". Sports Medicine, 40(7), 601-623. 2010.

[35] Van Poppel, M. N., Chinapaw, M. J., Mokkink, L. B., Van Mechelen, W., Terwee, C. B. "Physical activity questionnaires for adults”. Sports medicine, 40(7), 565-600. 2010.

[36] Lee, P. H., Yu, Y. Y., McDowell, I., Leung, G. M., Lam, T. H., \& Stewart, S. M, "Performance of the international physical activity questionnaire (short form) in subgroups of the Hong Kong Chinese population". International Journal of Behavioral Nutrition and Physical Activity, 8 (1), 81. 2011.

[37] Boon, R. M., Hamlin, M. J., Steel, G. D., Ross, J. J, "Validation of the New Zealand physical activity questionnaire (NZPAQ-LF) and the international physical activity questionnaire (IPAQ-LF) with accelerometry”. British journal of sports medicine, 44:741-6. 2010. 
[38] Oyeyemi, A. L., Umar, M., Oguche, F., Aliyu, S. U., \& Oyeyemi, A. Y, "Accelerometer-determined physical activity and its comparison with the International Physical Activity Questionnaire in a sample of Nigerian adults”. PloS one, 9(1), e87233. 2014.
[39] Kim, Y., Park, I., Kang, M, “Convergent validity of the international physical activity questionnaire (IPAQ): metaanalysis”. Public health nutrition, 16(3), 440-452. 2013. 